\title{
MITOLOGEMAS DE LO POLÍTICO: DEMOCRACIA Y PODER CONSTITUYENTE
}

\author{
Juan Pablo Arancibia Carrizo
}




\section{JUAN PABLO ARANCIBIA CARRIZO}

Doctor en Filosofía Política. Magíster en Filosofía Política. Licenciado en Comunicación. Profesor del Instituto de la Comunicación e Imagen de la Universidad de Chile. Su investigación se ha concentrado en la relación entre comunicación, filosofía y política. Autor de "Extraviar a Foucault" (2006, Palinodia); "Comunicación Política. Fragmentos para una genealogía de la mediatización en Chile (2006, U. Arcis): "Tragedia y Melancolía. Idea de lo trágico en la filosofía política contemporánea" (2016, La Cebra); y co-editor de "Comunicación política y democracia en América Latina” (2016, Gedisa). 


\section{MITOLOGEMAS DE LO POLÍTICO: DEMOCRACIA Y PODER CONSTITUYENTE}

Inscritos en la tradición moderno-contemporánea del pensamiento político, dos conceptos parecen crecientemente implicarse: "democracia" y "poderconstituyente". Desde cierta perspectiva, se podría afirmar que ambas figuras resultan actantes simbólicos fundacionales tanto para la teoría como para la experiencia política moderna. Por cierto, las dos escenografías históricas que cristalizan e imbrican aquellas figuraciones son la "Revolución Americana" de 1776 y la "Revolución Francesa" de 1789. Así, una amplia literatura política postula con insistencia que la democracia es más genuinamente democrática en cuanto ella emerge y se asienta en un proceso constituyente. Quizá esta persistente imbricación encuentre su origen en el doble y ambiguo uso que el propio Aristóteles tempranamente concede a la democracia, en ocasiones como régimen de gobierno, en otras, como principio de Constitución Política, ${ }^{1}$ de modo que - por herencia-, para gran parte del pensamiento moderno de lo político existiría un anudamiento consustancial entre la verdadera democracia y el poder constituyente.

Hablar del Poder Constituyente es hablar de Democracia. En la edad moderna, ambos conceptos se han desarrollado paralelamente y han estado insertos en un proceso histórico que, según se acercaba el siglo XX, los ha superpuesto cada vez más. Es decir, que el poder constituyente no ha sido sólo considerado la fuente omnipotente y expansiva que produce las normas constitucionales de todo ordenamiento jurídico, sino también el sujeto de esta producción (...) El poder constituyente tiende a identificarse con el concepto mismo de política, en la forma en la cual la política es entendida en una sociedad democrática. ${ }^{2}$

Sin embargo, al observar con atención el concepto mismo de "democracia" y su relación con la idea y principios del "poder constituyente", surge un conjunto de tensiones y complejidades que no siempre se dejan advertir, ni fácilmente resolver. En lo inmediato, nos limitaremos a atender parcial y muy brevemente

1. Aristóteles. Política. Madrid. Gredos. 1998. 1279ª

2. Negri, Antonio. El poder constituyente. Ensayo sobre las alternativas de la Modernidad. Madrid. Prodhufi. 1994. p.17. 
sólo tres ejes problemáticos. Primero, acerca de la efectividad histórica de dichos procesos, es decir, si son materialmente lo que ellos dicen que han sido. Segundo, las condiciones discursivas que harían posible tanto a la democracia como al movimiento constituyente que la funda y sostiene. Tercero, examen de algunos preceptos de la matriz teórica que define y comporta este anudamiento conceptual entre democracia y poder constituyente como principios fundacionales de la comunidad política moderna.

Primero, en torno a la efectividad histórica del poder constituyente y su carácter democrático. Desde cierta sensibilidad genealógica, cabría advertir que la Convención Constituyente Americana de 1787 se funda en una revolución que consagra el principio de independencia y soberanía, de modo que el movimiento constituyente emerge desde el colapso y crisis de un cierto régimen de orden. El proceso constituyente irrumpe y se configura como un modo de la crisis, de suerte tal que la Revolución de 1776 sería la condición de posibilidad del proceso constituyente de 1787. Sin embargo, de este proceso revolucionario-constituyente habría que recobrar algunos incidentes que impiden idealizar y normativizar su modulación.

Tal como nos lo explica Robert Dahl, la Convención Constituyente de 1787 se reunió en Filadelfia para ratificar la Constitución escrita desde 1785 por 155 redactores, de los cuales sólo 39 firmaron el documento final, que fue ratificado por convenciones en todos los estados y sólo en tres de ellos -Delaware, Nueva Jersey y Georgia - el voto fue unánime; en los estados restantes el voto fue dividido. En Massachusetts los delegados votaron 187 ratificando y 168 en contra; en New Hampshire el resultado fue de 57 sobre 46; en Virginia se ratificó la Constitución con 80 votos a favor sobre 79 votos en contra. De los 13 estados que debían refrendar la Constitución, Rhode Island se negó a asistir, y los delegados de New Hampshire arribaron con varias semanas de retraso. Finalmente, la Constitución Americana de 1787 fue aprobada por menos de dos mil hombres, muchos de ellos hacendados y dueños de esclavos. De los 55 redactores de la Constitución, sólo ocho habían firmado también la Declaración de Independencia, y de los "Padres Fundadores" de la Nación Americana — John Adams, Samuel Adams, Tom Paine y Thomas Jefferson-, ninguno de ellos estuvo presente en la Convención Constituyente de $1787 .^{3}$

Por su parte, en el proceso revolucionario francés, en julio de 1789, la Asamblea Nacional Constituyente contó con 490 votos a favor de su Constitución y 90 votos

3. Dahl, Robert. ¿Es democrática la constitución de los Estados Unidos? Buenos Aires, Argentina. Fondo de Cultura Económica. 2003. pp.9-13. 
en contra. Tocqueville explica que la conformación revolucionaria de la Asamblea Nacional Constituyente sólo habría sido el resultado lógico de un régimen históricamente opresivo de la voluntad y la soberanía del pueblo. Dado que el pueblo no había hecho acto de presencia ni por un instante desde hacía 140 años en la escena de los asuntos públicos, se había dejado absolutamente de creer que pudiera reaparecer en ella; y al verlo tan insensible, lo juzgaban sordo. "Quienes más debían temer su cólera conversaban en voz alta y frente a él de las crueles injusticias de que siempre había sido víctima: se mostraban unos a otros los espantosos vicios que encerraban las instituciones que más lo agobiaban, y empleaban su retórica para describir sus miserias y su mal remunerado trabajo".

En la Asamblea Provincial de la Baja Normandía, en 1787, los delegados locales afirmaban: "Estamos cansados de ver que el dinero asignado por el rey a carreteras sólo promueve el bienestar del rico sin ser útil para el pueblo". Mientras que en la Asamblea Provincial de la Alta Guyena, hablando de esos campesinos por cuya causa se abogaba calurosamente, las clases aristocráticas los llamaban "seres ignorantes y groseros, seres turbulentos y caracteres rudos e indóciles". A medida que se acerca 1789, escribe Tocqueville, esta simpatía por las miserias del pueblo es más viva e imprudente. "He tenido en mis manos circulares que varias asambleas provinciales dirigían, en los primeros días de 1788, a los habitantes de distintas parroquias, a fin de conocer por ellos mismos y en detalle de cuántos agravios habían sido víctimas"

Después de dos años de Asamblea Nacional Constituyente, ésta fue sustituida por la Asamblea Legislativa de septiembre de 1791. Tras el proceso revolucionario, explica Tocqueville, la aristocracia francesa mantuvo sus privilegios a pesar de haber perdido su poder político, tornándose una clase aislada y rechazada por todos los grupos sociales; el régimen absolutista abolió las libertades provinciales deviniendo un centralismo administrativo; la burguesía económica se centró en los negocios y carecía de la cultura cívico-política de participar en los asuntos públicos; la casta intelectual profirió ideas revolucionarias y filantrópicas, las que fueron asumidas violentamente por un pueblo acostumbrado al sometimiento y el yugo; sumado a la clásica complicidad entre la Iglesia y los sectores más conservadores y reaccionarios del Antiguo Régimen; añadida la confusión entre los principios de igualdad y de libertad, finalmente, hacen de este proceso un intento frustrado, desembocando en un régimen despótico que se corresponde con las condiciones sociales creadas por el Antiguo Régimen. De modo que la sociedad post-revolucionaria deviene en un

4. Tocqueville, Alexis. El antiguo régimen y la revolución. México. Fondo de Cultura Económica. 2000. p.291.

5. Ibid. pp.291-296. 
orden social donde prima el desprecio a la autoridad, la que sólo se sostiene por el miedo que infunde su violencia; se acrecienta e intensifica la brecha y la guerra entre ricos y pobres; se produce una debilidad común y una ausencia casi total del poder colectivo, donde gobiernan los prejuicios y la ignorancia carente de virtud y donde el pueblo ya no tiene el coraje de cambiar, pues prima la pasión de los "hombres viejos".

Pese a su intrincada y conflictiva configuración, tanto la Revolución Americana como la Revolución Francesa han servido de paradigmas normativos para la constitución del mitologema "democrático-constituyente" que ha operado como clave explicativa, y al mismo tiempo, como horizonte de sentido de toda una narratología política moderno-contemporánea. Los 200 años de la "República de Chile", por cierto, no han estado exentos de estas figuraciones. Si bien tradicionalmente se afirma que en Chile nunca se ha llevado a cabo una asamblea constituyente, esto no necesariamente implica la ausencia de procesos históricos que han pulsado y litigado por su afirmación.

Tal como nos explica el Profesor Gabriel Salazar, habría un vacío u olvido en la tradición política de las experiencias constituyentes en Chile, básicamente, por dos causas fundamentales. Primero, "porque cada vez que el movimiento popular ha ejercido de propia mano el poder constituyente, la clase dirigente lo ha reprimido brutalmente y, al derrocarlo, ha mitificado el discurso de los vencedores, denigrando y sepultando en el olvido al de los perdedores". Segundo, "porque la Izquierda Parlamentaria se alojó e identificó con las normas del Estado Liberal de 1925 y por ello se asumió por sí y para sí la vanguardia política del movimiento popular, reduciendo a éste sólo como movimiento de masas incapaces de ejercer por sí mismas el poder constituyente, lo que devaluó y sepultó en el olvido de la historia oficial de izquierda el discurso del poder popular constituyente" 7.

En 200 años de historia, la clase dirigente mercantil no ha admitido nunca, por convicción e interés, ningún ejercicio público del poder popular constituyente. Es que, si lo admitiera, sería su muerte histórica (...) La conclusión es que el obstáculo que frena, obstruye y reprime al poder popular constituyente está formado por los intereses específicos y conjuntos de la clase política civil, que en este aspecto crucial ha contado y cuenta con el no despreciable apoyo de la clase política militar ${ }^{8}$.

\footnotetext{
6. Ibid. pp.20-49.

7. Salazar, Gabriel. En el nombre del poder popular constituyente. Chile, Siglo XXI. Santiago, Chile. Lom. 2011. p.28.

8. Ibid. p.29.
} 
Desde la perspectiva de la Historia Social, sostiene Salazar, en Chile se registran al menos dos procesos afirmativos del poder popular constituyente: el movimiento social-ciudadano del período 1822-1828, y el movimiento social-ciudadano del período 1918-1925. En el primero, durante 1822, se produjeron alzamientos y desobediencia civil contra la dictadura de O'Higgins y se conformaron las Asambleas de Pueblos Libres de Concepción y Coquimbo. El dictador organizó su fuerza militar para aplastar la rebelión, pero finalmente fue forzado a abdicar. El comandante en jefe del Ejército, general Ramón Freire, emprendió la tarea de organizar una asamblea nacional constituyente. El proceso constituyente se inició en 1823 y el pueblo discutió los principios fundamentales que debían estructurar el Estado y esto se convirtió en mandato ciudadano para los diputados que realizarían la asamblea constituyente. Sin embargo, el conflicto de 1822, todavía latente, estalló al interior de la asamblea y finalmente la hizo fracasar. El patriciado mercantil-monopolista desplegó diversas acciones para sabotear y derrotar a las fuerzas populares: una ofensiva de burlas y mofas para desacreditar a los delegados provinciales, obstrucción y distorsión de los debates, monopolizaron la redacción del texto resolutivo preservando el carácter aristocrático y centralista de la Constitución — redactada por Juan Egaña en 1823—; retardaron la discusión de esa propuesta para que los detractores y representantes populares tuvieran que regresar a sus pueblos y una vez que se había desmembrado la mayoría popular, procedieron a imponer su Constitución. Esto, nuevamente, produjo motines y alzamientos, por lo que el general Freire abolió esa Constitución aristocrática y se reemprendió un proceso constituyente en 1824 y 1826, ambos nuevamente fracasados por el sabotaje del patriciado mercantil, consiguiendo esta vez la renuncia de Freire. Se convoca una nueva asamblea constituyente en 1828, sesionada en Valparaíso, y se consiguió la Constitución Popular Representativa?.

La Constitución de 1828 ha sido en dos siglos de historia, la única acordada libremente por la ciudadanía chilena... La aprobación y promulgación de la Constitución de 1828 significó, por tanto, la derrota estratégica del patriciado mercantil de la capital. Era el eclipse total del resabio centralista del Estado Colonial Español, en sus ramales chilenos. Era la defenestración del totalitarismo santiaguino. Y el triunfo, por el contrario, del social-productivismo democrático sostenido por los pueblos de provincia, el artesanado de todas partes, las milicias ciudadanas del Ejército y por algunos prohombres liberales del patriciado de la capital. Y, por supuesto, por el general Ramón Freire ${ }^{10}$.

$9 \quad$ Ibid. pp.31-47.

10 Ibid. p.47. 
Ante esta derrota política, el patriciado mercantil, encabezado por Diego Portales, organizó otro ejército paralelo y mercenario, asestando un golpe de Estado y provocando la primera guerra civil de la naciente república. Las fuerzas constitucionales de Freire derrotan a los golpistas de Portales y del general Joaquín Prieto. Cuando se prepara el armisticio de los golpistas, Prieto tiende una trampa a las tropas constitucionales y les arresta. Más tarde, en la batalla de Lircay, en 1829, Freire es derrotado, se asesina a los oficiales constitucionales y se impone la dictadura de Portales y Prieto ${ }^{11}$. Tras su victoria en Lircay, la oligarquía se apoderó resueltamente del gobierno, controló militarmente el país y organizó férreamente el Estado del patriciado mercantil, con un fuerte resguardo y respaldo de su nuevo ejército. ${ }^{12}$

En el segundo movimiento social-ciudadano de 1918, los trabajadores convocan a todos los actores sociales a constituir la Asamblea Obrera de Alimentación Nacional como medida para impulsar un proceso de deliberación ciudadana y proponer leyes necesarias para reactivar la economía y detener la inflación y la miseria que asolaba al pueblo. Con masiva participación se estableció un Congreso Popular paralelo para legislar, iniciando con ello el ejercicio del poder popular constituyente. Tras la organización de los comicios locales, las comunidades deliberaron y redactaron medidas y proyectos de ley. Luego organizaron las "marchas del hambre" y acudieron a entregar los proyectos de la Cámara Legislativa Popular directamente al Presidente en La Moneda. El Gobierno reaccionó decretando Ley Marcial tras indicios de una posible guerra con Perú y bajo el amparo de esa misma ordenanza se dispuso a eliminar a los enemigos internos subversivos, y se arrestó a los dirigentes del movimiento en todo el país. Luego, entre 1923 y 1925, reaparece la idea del poder popular co-legislativo, ahora centrado en promover un sistema educacional para la nueva república. Nuevamente la respuesta fue represión, cárcel y relegamiento para los dirigentes. Pese a esto, el movimiento popular se autoconvocó a una Asamblea Constituyente de Asalariados e Intelectuales — realizada en el Teatro Municipal de Santiago en marzo de 1925-, destinada a preparar y convocar una asamblea nacional constituyente. Ésta última nunca se realizó, pues Arturo Alessandri Palma, retornado del destierro para organizar la asamblea nacional constituyente, prefirió convocar a una comisión de expertos y notables para redactar e instaurar una nueva Constitución, destinada a "reconstruir la República sin odios ni rencores, y

11. Ibid. pp.47-51.

12. Vicuña, Carlos. La tiranía en Chile. Santiago, Chile. Lom. 2002. pp.41-58. 
consolidar la obra generosa de la revolución militar". ${ }^{13}$ Finalmente, la Constitución de 1925 fue aprobada en un plebiscito con casi un 60\% de abstención ciudadana. ${ }^{14}$

Tanto la Constitución portaliana de 1833, la de Alessandri en 1925, como la de Pinochet-Guzmán en 1980, son portadoras de un principio y estatuto común: son dispositivos jurídico-políticos ${ }^{15}$ de negación y cruento aplastamiento de la soberanía del pueblo y la ciudadanía. Si algo se torna nítido y evidente en todos estos procesos, es la más palmaria y flagrante privación de la palabra y autodeterminación de la comunidad política. De allí que recobre relevancia la pregunta que Foucault formulara en 1970: “¿Cuál es el peligro de que la gente hable? ¿Por qué es preciso para la conservación del orden, ejercer una economía política de privación de la palabra y el discurso?" 16 . Si consideramos que la teoría política moderna insistentemente enseña que la democracia sólo es genuinamente democrática en cuanto ella reposa en la soberanía y autodeterminación de la comunidad, y su máxima jurídica es el ejercicio del poder soberano expresado en la asamblea constituyente, entonces cabría preguntar: ¿qué se juega en el ejercicio de esta privación y constricción de la palabra soberana? ¿Cuál es el peligro que se quiere conjurar impidiendo a toda costa que el pueblo y la ciudadanía resuelvan soberanamente los principios que habrán de regir su vida en común? ¿Qué tipo de poder es el que opera y se defiende mediante esta privación? ¿Cuáles han sido las fuerzas que históricamente han operado en la Constitución de 1833, en la de 1925 y en la de 1980? Y lo que resulta obvio preguntar: ¿Cuáles serían aquellos poderes y las correlaciones de fuerza que habrían de operar en este nuevo proceso constituyente?

Estas preguntas, en lo inmediato, nos conducen al examen de la segunda cuestión aquí abordada, concerniente a las condiciones discursivas que harían posible tanto la democracia como el movimiento constituyente que la funda y sostiene. Gran parte de la teoría política clásica y moderna enseña que para que exista democracia habrá de garantizarse cierto conjunto de condiciones políticas y jurídicas que conformen el orden discursivo que posibilite y preserve su existencia y ejercicio. ${ }^{17}$ En lo fundamental se reconocen tres: isegoría, isonomía y parrhesía. Las dos primeras obedecen a un carácter jurídico formal, en cuanto constituyen requisitos o exigencias reglamentarias para acreditar el régimen discursivo de la democracia.

13. Ibid. pp.307-323.

14. Op. Cit. Salazar. En el nombre del poder popular constituyente. pp.67-72.

15. Deleuze, Gilles. Qué es un dispositivo. En, Balbier, E. Michel Foucault, Filósofo. Barcelona. Gedisa. 1999. pp. 155-163.

16. Foucault, Michel. El orden del discurso. Barcelona. Tusquets. 2002. pp.14-25.

17. Forrest, W.G. La democracia griega. Trayectoria política del 800 al 400 a.C. Madrid. Guadarrama. 1966. pp.9-44. 
La tercera de ellas, sin embargo, excede el orden de la judicatura formal y se define como portadora del carácter ético o "virtuoso" que distingue y sostiene la tradición democrática, cual es el "hablar libremente". Este hablar libre no se refiere sólo al sentido de su posibilidad legal y formal, sino a su densidad ético-material, esto es, el ejercicio de hablar "en nombre de la libertad". De allí que desde la antigüedad la democracia será asociada a la libertad de los discursos o, más precisamente, al discurso de la libertad. ${ }^{18}$

La isegoría - como primera condición discursiva de la democracia - concernía al derecho de hablar, al derecho estatuido de un ciudadano para "tomar la palabra" y expresar libremente su juicio sobre lo perjudicial (blaberon) y lo ventajoso (sympheron) para la comunidad política; ${ }^{19}$ mientras que la isonomía refería al valor o legitimidad que funda esa palabra, esto es, la igualdad ante la ley que cada ciudadano porta y constituye la misma valía en el derecho. Estos principios de isegoría e isonomía no sólo preservaban la igualdad, dignidad y el valor jurídico de cada ciudadano (civites), sino que, a su vez, consagran la propia universalidad del derecho que asienta la democracia.

La tercera condición define y comporta la densidad ético-discursiva de la democracia: la parrbesía. Ésta, básicamente, se refiere a un tipo de hablar público que presenta ciertas singularidades: se trata de tomar la palabra públicamente para hablar ante el poder, pero especialmente concierne a tomar la palabra públicamente para impugnar, contrariar o desafiar ese poder. Se trata de un decir adversativo, que reclama del orador el valor, el saber, pero también la ética, la ascendencia y la virtud para proclamar lo que es bueno y justo para la ciudad, aunque aquella declamación contravenga a la propia asamblea y directamente se oponga al "poder" que gobierna la comunidad. En ese sentido, la parrbesía es un discurso agonal, ético y estético, en cuanto no se juega ni explica por la utilidad o carácter instrumental de su decir; antes bien, se trata de un discurso con arreglo a principios, destinado a decir la verdad adversativa al poder, aunque para ello se corra el riesgo de enfrentar las máximas represalias y castigos. Por esta razón, dada la implicancia ético-política de la parrhesía, no se limita a ser un derecho formalmente grabado en el código y universalmente reservado a todo ciudadano, sino que es un valor y una virtud ética singular de quien porta el coraje y se arroja al riesgo de decir públicamente una verdad prohibida que desafía y confronta un poder. Si, formalmente, todo ciudadano tendría la facultad jurídica universal de ejercer el "derecho" a la práctica parrhesiástica, lo cierto es

18. Aron, Raymond. Ensayo sobre las libertades. México. Alianza. 1990.

19. Rancière, Jacques. El desacuerdo. Política y filosofía. Buenos Aires, Argentina. Nueva Visión. 1996. pp.13-19. 
que ella sólo se ejerce como acto ético, esto es, escasamente. Así, la parrhesía estaría constituida por una relación con la verdad, con el coraje, con la demanda de justicia y con disputar el bien de la comunidad política. Dicho en los términos de Foucault, el "cuadrilátero parrhesiástico", la práctica de parrhesía consistiría en: primero, el principio de la democracia como régimen de igualdad y libertad; segundo, el principio de ascendiente o superioridad ética de quien toma el riesgo y profiere la palabra litigante; tercero, el principio de un decir veraz inspirado en la verdad; y cuarto, el principio de la justa o discurso agonístico, un enfrentamiento con el poder al que se critica e interpela. ${ }^{20}$

Tan cruciales, decisivas y distintivas para la cuestión democrática resultan estas tres condiciones, que una amplia y diversa literatura afirma que sin estos valores o principios, la democracia misma no existiría ${ }^{21}$. La complejidad de tal cuestión forzaría a examinar entonces, primero, si estas condiciones de isegoría, isonomía y parrhesía se cumplen efectivamente en la sociedad tecnocapitalista de democracias mediatizadas. Segundo, si éstas no se acreditaran en su práctica y su sentido más genuino y severo con que fueron inspiradas, ¿qué posibilidades le restan a la propia democracia para reconstituir el tejido ciudadano para un hablar cívico que reinaugure y potencie aquello que la define y preserva, el principio de soberanía de la comunidad? ¿Qué condiciones discursivas exigiría un proceso constituyente destinado a superar una crisis del orden general y hacer emerger nuevas condiciones de una contrademocracia ${ }^{22}$ que revitalice y profundice el pacto democrático? Y por último, ¿cuál sería el carácter de un proceso constituyente que no asegurase este triple principio democrático donde, primero, todos puedan hablar; segundo, que ese hablar deliberante cuente, valga, se registre y regimente en la decisión soberana de la comunidad; y tercero, que en ese hablar de la comunidad el propio poder se exponga y arriesgue a ser él mismo, transformado o destituido? ¿Qué ocurriría si en el marco de un proceso constituyente ninguna de estas condiciones se cumplen? Estas preguntas elementales conducirían a plantear el tercer problema: repensar la cuestión democrática.

Que la democracia sea inscrita como un mitologema de lo político no quiere decir que sea falsa, sino más bien quiere decir que en cuanto ella misma profiere condiciones discursivas de autoafirmación, performativamente ella misma se

20. Foucault, Michel. El gobierno de sí y de los otros. Buenos Aires, Argentina. Fondo de Cultura Económica. 2009. pp.233-265.

21. Rancière, Jacques. El reparto de lo sensible. Estética y política. Santiago, Chile. Lom. 2009. pp.9-19.

22. Rosanvallon, Pierre. La contrademocracia. La política en la era de la desconfianza. Buenos Aires, Argentina. Manantial. 2007. pp. 35-78. 
constituye. ${ }^{23}$ Esto implica que el anudamiento progresivo entre democracia y poder constituyente ha operado como vector analítico y mitopoiético de la razón política moderna. En los mitos fundacionales de la experiencia política moderna - la Revolución Americana y la Revolución Francesa-, aquella articulación entre democracia y poder constituyente está imbricada y asentada en profundas crisis políticas, económicas y morales. Lo que en esos mitologemas no siempre se deja advertir es que lo que anuda y acopla el mito de la democracia y el poder constituyente es la idea de crisis o, más exactamente, el carácter inaugural, fundacional y podríamos decir, excepcional, de la comunidad política ${ }^{24}$.

Quizá nunca como en el curso de la revolución francesa, este imperativo transformar el poder constituyente en poder extraordinario, aplastarlo sobre el acontecimiento y cerrarlo en una fatuidad sólo revelada por el derecho- ha sido tan afanosamente sentido. El poder constituyente como poder omnipotente es, en efecto, la revolución misma ${ }^{25}$.

De este modo, tanto la teoría política como la teoría jurídica han inscrito el poder constituyente en relación a una crisis. El poder constituyente sería el concepto democrático y agonístico ${ }^{26}$ de una crisis, pues hace forzosamente referencia al colapso o agotamiento de un orden y a la emergencia de otro. Sea bajo la figura del poder constituyente originario o la de poder constituyente derivado, éste deviene de la crisis. Conspicuos estudiosos y pensadores contemporáneos han planteado la pregunta por la relación más íntima que habría entre democracia y crisis, y muy particularmente por el estado actual de la democracia en la sociedad postindustrial. ${ }^{27}$ Giorgio Agamben interroga la pertinencia del concepto mismo de democracia en cuanto ella configura la categoría política que piensa y explica nuestro presente. Advierte que todo el discurso actual sobre el término "democracia" está cruzado y constituido por una ambigüedad preliminar que nos condena a un malentendido: por un lado la democracia se concibe como la constitución del cuerpo político; por

23. Barthes, Roland. Mitologías. México. Siglo XXI. 2002. pp.199-229.

24. Zizek, Slavoj. ¿Quién dijo totalitarismo? Valencia. Pre-Textos. 2002. pp.261-291.

25. Op. Cit. Negri. El poder constituyente. pp.18-19.

26. Mouffe, Chantal. En torno a lo político. Buenos Aires, Argentina. Fondo de Cultura Económica. 2007. pp.15-32.

27. Wolin, Sheldon. Democracia S.A. La democracia dirigida y el fantasma del totalitarismo invertido. Buenos Aires, Argentina. Katz. 2008. pp.11-20. 
otro, como una técnica de gobierno, es decir, designa tanto la forma de legitimación del poder como las modalidades administrativas de su ejercicio ${ }^{28}$.

Esta anfibología democrática se remonta a la democracia griega, donde se proferían distintas voces co-implicadas. En el mundo clásico la expresión politeiai remitía a los principios de constitución de la comunidad política, la noción de politeia concernía a la actividad política, mientras que politeuma refería a la cosa política, y a su vez estas nociones estaban cruzadas por el concepto de kyrion que alude al principio del poder soberano. Para la teoría política moderna estas nomenclaturas fueron heredadas de modo que politeia fue concebida y traducida como el poder constituyente, mientras que politeuma como el poder constituido. Ambas nociones sostenidas e implicadas en el kyrion entendido como el poder soberano. Esta ambigüedad ha implicado que, para unos, la democracia opera como los principios de la soberanía popular y su máxima sería el poder constituyente; mientras que para otros la democracia es la mera forma administrativa y económica de la comunidad.

Si hoy en día presenciamos la dominación aplastante del gobierno y la economía sobre una soberanía popular que ha sido progresivamente vaciada de todo sentido, es tal vez porque las democracias occidentales están pagando el precio de una herencia filosófica (...) El mal entendido que implica concebir el gobierno como un simple poder ejecutivo es uno de los errores con mayores consecuencias en la historia de la política occidental ${ }^{29}$.

Agamben sostiene que en esta ambigüedad se oculta la más radical tensión del pensamiento y la experiencia política moderna: "¿No se tratará de una ficción, destinada a disimular el hecho de que el centro de la máquina esté vacío, que no haya, entre los dos elementos y las dos racionalidades, ninguna articulación posible?". ${ }^{30}$ Jean-Luc Nancy insiste en el problema y replantea la pregunta: ¿Tiene hoy sentido usar el rótulo de democracia? ¿Sirve para algo definirse como demócrata? ¿No es acaso la democracia un término cuya fraseología es tan ambivalente que sirve tanto para afirmar cierto conjunto de valores, principios y prácticas, pero al mismo tiempo también para negarlos e impedirlos?

28. Agamben, Giorgio. Democracia, ¿en qué estado? Buenos Aires, Argentina. Prometeo. 2010. p.11.

29. Ibid. p.12.

30. Ibid. p.12. 
La democracia se ha convertido en un caso ejemplar de la insignificancia: con vistas a representar el todo de la política virtuosa y como única manera de garantizar el bien común, la palabra ha llegado a absorber y disolver todo carácter problemático, toda posibilidad de interrogación o cuestionamiento (...) La democracia pretende englobar todo — política, ética, derecho, civilizacióny no significa nada ${ }^{31}$.

Así, la instauración y naturalización de la jerga democrática ha terminado por diluir y encubrir el carácter siempre frágil y problemático de la propia democracia, operando un cierto extrañamiento entre pensamiento y política ${ }^{32}$. Nancy explica que la democracia, desde su origen griego, es lo otro de la teocracia y es también lo otro del derecho determinado y, en ese sentido, la democracia debe inventar su propio derecho, es decir, debe inventarse a sí misma. En consecuencia, la democracia ha vivido históricamente aquejada del problema de tener que fundarse y reinventarse de forma permanente. Es precisamente en el devenir de esa invención democrática que ella se trasluce como un lugar vacío, ${ }^{33}$ y en el curso de esa reinvención histórica la democracia ha querido transferir la soberanía al pueblo y se ha entroncado con la idea del poder constituyente, y con el solo uso de aquella referencia ha dejado en total evidencia que el principio de soberanía carece de fundamento. Esto implicaría que la democracia se ha vuelto una religión civil, puesto que, en última instancia, la política misma carece de fundamento. Pero cuando se le ha querido dar alguno - la razón, el derecho, el Estado, el mito nacional—, entonces ha devenido dominación y opresión. ${ }^{34}$ Curiosamente, lo que una cierta teoría política convencional ha tendido a omitir es la relación entre poder constituyente y stasis, que es el concepto con que los griegos antiguos designaban el proceso de crisis y confrontación interna de la comunidad política, lo que más tarde se designó "guerra civil" ${ }^{35}$ Lo que aquella categoría muestra conceptual e históricamente es el carácter infundado y afirmativo de una relación de fuerza que se pone a sí misma como fundamento y principio

31. Nancy, Jean-Luc. Democracia finita e infinita. En, Agamben, G. Democracia ¿en qué estado? Buenos Aires, Argentina. Prometeo. 2010. pp.67.

32. Esposito, Roberto. Confines de lo político. Nueve pensamientos sobre política. Editorial Trotta. Madrid, 1996. pp. 19-37.

33. Lefort, Claude. La invención democrática. Buenos Aires, Argentina. Nueva Visión. 1990. pp.187-193.

34. Op. Cit. Nancy. Democracia finita e infinita. p.69.

35. Agamben, Giorgio. La guerra civil. Para una teoría política de la Stasis. París. Points. 2015. pp.931. 
orgánico de la comunidad, y es precisamente ese movimiento afirmativo el soporte infundado sobre el cual reposa la experiencia histórica de la democracia.

Así la democracia requiere de una verdadera revolución: la transformación de la propia base de la política. Debe exponerse a la falta de fundamento, pero no permite que la revolución vuelva al supuesto punto de fundamento. Revolución suspendida entonces ${ }^{36}$.

Esta desfundamentación de la democracia pareciera ya habitar en su propio vocablo. La expresión “democracia”, enseña Nancy, está formada por el sufijo cracia que concierne a la fuerza y la imposición violenta, a diferencia de arquía, que se refiere a un poder fundado y legitimado desde un principio. Esto se hace evidente en gobiernos como la plutocracia, aristocracia, teocracia, tecnocracia, autocracia, burocracia, oclocracia, que se distinguen de la monarquía, anarquía, oligarquía, donde la arquía se divisa como la designación de un principio fundador que es claramente distinto a la imputación de una fuerza dominante.

Lo cierto es que la palabra democracia parece negar la posibilidad de un principio fundador. En efecto, la democracia esencialmente implica una especie de "anarquía" primordial (...) Es por eso que el derecho al que se refiere la institución democrática sólo puede vivir en la verdad en el contexto de una relación permanentemente activa y renovada por su propia falta de fundamento ${ }^{37}$.

Esto nos retorna al carácter excepcional de la democracia en cuanto ella misma ha de reposar en un poder infundado que requiere constituirse como poder, cuestión que torna evidente el carácter siempre exterior y excepcional del principio organizativo de la comunidad política. He ahí la paradoja de un poder que surge de la nada y organiza todo el derecho. Tal como plantea Botmy: "El poder constituyente es un acto imperativo de la nación que surge de la nada y organiza toda la jerarquía de los poderes". Esto determina el carácter de excepcionalidad jurídica sobre la cual se asienta la fundación de la comunidad política, y al mismo tiempo acusa y notifica su propia vulnerabilidad. Así se advierte la inquietante contigüidad esencial que existiría entre el estado de excepción y la soberanía ${ }^{38}$, cuya máxima necessitas legem non habet se presenta como el estado de necesidad sobre la cual se funda la excepción

36. Op. Cit. Nancy. Democracia finita e infinita. p.71.

37. Ibid. p.73

38. Schmitt, Carl. El concepto de lo político. Madrid. Alianza. 2006. pp.49-83. 
y por lo cual no puede tener forma jurídica. Aquello seña la opaca y problemática frontera entre la política y el derecho, es decir, el estado de excepción torna sombrío el límite entre la forma legal de aquello que no puede tener forma legal. ${ }^{39}$

En ese sentido, Burdeau afirma que "La potencia que esconde el poder constituyente es rebelde a una integración total en un sistema jerarquizado de normas y competencias, de cierta manera se podría decir que siempre el poder constituyente permanece extraño al derecho". ${ }^{40}$ Esto implica, sostiene Nancy, que si el pueblo es el soberano y en última instancia esa soberanía no es nada, no se deposita ni se figura en ninguna persona, en nada que esté por encima, ni en Dios ni en amo alguno, "entonces toda la posibilidad de la democracia equivale a su anarquía".

Una anarquía que induce a acciones, operaciones, combates, formalizaciones, que permiten preservar rigurosamente la ausencia de arquía puesta, expuesta e impuesta. El kratein democrático, el poder del pueblo, es ante todo el poder de echar por tierra la arquía y, a continuación, hacernos cargo, todos y cada uno, de la apertura infinita así puesta en evidencia ${ }^{41}$.

De allí que la democracia pueda ser pensada como categoría impolítica, ${ }^{42}$ es decir, como aquel régimen cuya verdad no puede ser representada ni subsumida en ninguna instancia ordenadora, ni religiosa, ni política, ni científica, ni estética, pero que compromete por entero al hombre en cuanto riesgo y posibilidad de si mismo. ${ }^{43} \mathrm{De}$ este modo la democracia trenza su nervadura más íntima con el carácter constituyente de la comunidad, que se genera y regenera agonística y adversativamente dispuesta, a tal rango que decir "poder constituyente" habría de querer decir: democracia puesta en movimiento, esto es, el principio de determinación libre y soberana de la comunidad política.

Desde la perspectiva de la teoría jurídica, el poder constituyente es la fuente de producción de las normas constitucionales, o bien el poder de hacer una constitución y de dictar las normas fundamentales que organizan los poderes

39. Agamben, Giorgio. Estado de excepción. Bueno Aires, Argentina. Adriana Hidalgo. 2004. pp.23-25.

40.. Burdeau, G. Tratado de ciencias políticas. París. Gallimard. 1983. p.171.

41. Nancy, Jean-Luc. La verdad de la democracia. Buenos Aires, Argentina. Amorrortu. 2008. pp.54-57.

42. Esposito, Roberto. Categorías de lo impolítico. Buenos Aires, Argentina. Katz. 2006. pp.29-43.

43. Op. Cit. Nancy. La verdad de la democracia. pp.57. 
del Estado; es el poder de instaurar un nuevo ordenamiento jurídico, esto es, de regular las relaciones jurídicas en el seno de una nueva definición de la comunidad política ${ }^{44}$.

Pensado así el problema, cabría preguntar, entonces: ¿cuáles serían aquellas condiciones para que emerja la palabra soberana? En este nuevo reparto de lo sensible, ¿quién tiene derecho a hablar y quién no? ¿Quién administra y traza ese derecho? Y por cierto, ¿cuál es la eficacia y la densidad performativa de esa palabra, que emerge infundada pero deviene ley? Si un proceso constituyente proclama y reclama que la gente hable, la cuestión ahora concierne a ¿qué harán con aquellas palabras? Para que exista democracia, nos recuerda Rancière, la esencia y toda la potencia de la palabra política en el espacio agonal del "demos" ha de estar constituida por la posibilidad cierta de su concretitud, de su pesada y temible materialidad, de su performatividad, de su potencial e inquietante poder transformador. La isegoría no se limita a garantizar el derecho formal de "poder decir", antes bien, asegura el "poder de su decir", esto significa que la densidad de su palabra "vale", "cuenta", se "registra" y "decide" políticamente; pero además, la isonomía garantiza que esa palabra ya dicha valga lo mismo y nunca menos que la de otro ciudadano, es decir, su palabra nunca es subalterna, súbdita o minusválida respecto de otra, esto es, en fin de cuentas, la igualdad de derecho y la igualdad ante el derecho ${ }^{45}$. De este modo, si calificar constitucionalmente, jurídicamente, el poder constituyente no será pues simplemente producir normas constitucionales, estructurar poderes constituidos, sino, sobre todo, ordenar el poder constituyente en cuanto "sujeto", esto es, regular la política democrática ${ }^{46}$. Entonces es preciso preguntar ¿cuál será el sujeto que produzca y modele el devenir de la comunidad? Si la democracia es un mitologema de lo político, implica que ella misma se produce y reproduce mitopoiéticamente bajo condiciones y relaciones de fuerza específicas y acotadas. Para que el mito sea mito, es preciso que éste se haga cierto. ¿Cuál será entonces la economía discursiva que regule y gobierne el nuevo trazado y la judicatura del orden que adviene? Precisamente allí, una muy razonable inquietud asoma: ¿qué diferencia habrá entre esta experiencia y las anteriores?

44. Op. Cit. Negri. Poder constituyente. p.18.

45. Op. Cit. Rancière. El reparto de lo sensible. pp.9-19.

46. Op. Cit. Negri. Poder constituyente. p.17. 